\title{
The Communicative and Cognitive Deficits Following Closed-Head Injury
}

\author{
Lesley Irvine, BA (Sp. \& H. Therapy) (Witwatersrand) \\ Marlene Behrmann, MA (Speech Path.) (Witwatersrand) \\ Department of Speech Pathology and Audiology, \\ University of the Witwatersrand, Johannesburg.
}

\section{ABSTRACT}

The communicative and cognitive deficits of three closed-head injured patients were investigated within the framework of language form. Tanguage use and cognitive ability. A battery of tests was administered and results indicated a degree of cognitive impairment in all subjects. The balance between the language form and language use skills was subject-specific. These findings supported the current view of heterogeneity within the closed-head injured population as well as the view that a language disorder may result from an underlying cognitive deficit. The results are discussed in the light of the existing literature on head injury. The theoretical and clinical implications are considered.

\section{OPSOMMING}

Die kommunikatiewe and kognitiewe vermoëns van drie geslotehoofbeseringspasiënte is ondersoek binne die raamwerk van taalvorm, taalgebruik en kognisie. ' $n$ Toetsbattery is gebruik en volgens die resultate was daar' $n$ mate van kognitiewe en kommunikatiewe aantasting in al drie proefpersone. Die verhouding tussen taalvorm-en gebruiksvaardighede was proefpersoonspesifiek. Hierdie bevindinge ondersteun die huidige sienswyse van heterogeniteit binne die geslotehoofbeseringspopulasie sowel as die opvatting dat 'n taalafwyking die gevolg van' $n$ onderliggende kognitiewe afwyking kan wees. Die resultate word teen die agtergrond van bestaande literatuur oor geslotehoofbesering bespreek. Daar is ook op beide die teoretiese and kliniese implikasies ingegaan.

Closed-head injury (CHI) has recently been termed "the invisible epidemic" (Holland, 1982) in view of the well documented dramatic increase in the incidence of this disorder (Annegers, Grabow, Kurland and Laws, 1980). The primary source of the pathophysiology in $\mathrm{CHI}$ is that of blunt trauma to the brain which results in discontinuation of neural substance and shearing and straining of the axons in the white brain matter (Hagen 1984). While there seems to be agreement concerning the neurological symptoms of this disorder, considerable controversy still surrounds the neurobehavioural and linguistic sequelae. Hagen (1984) has called for controlled, systematic research into the communicative and cognitive deficits which follow $\mathrm{CHI}$ in order to clarify the existing confusion. From a clinical point of view, the need for further research is pressing in view of the fact that decisions regarding management of $\mathrm{CHI}$ individuals must be made.

The language symptomatology resulting from $\mathrm{CHI}$ constitutes an area of much controversy. Some writers have considered the language disturbance to be an aphasia (Luria, 1970) while others have argued that the language disorder is unique and clearly distinguishable from classical aphasia (Holland, 1982). Sarno (1980, 1984) has identified three subtypes of $\mathrm{CHI}$ subjects, each subtype demonstrating some degree of llanguage impairment. The one subtype exhibits the traditional aphasic symptoms whilst the remaining two subgroups display subclinical aphasia or a language processing problem without the overt manifestation of classical aphasia. According to Sarno $(1980 ; 1984)$, the typical features of all $\mathrm{CHI}$ subjects include reduced word fluency, impaired comprehension of complex oral commands and an anomia. It has been suggested that such subtle language problems may only be detected through the use of sophisticated neurolinguistic assessment procedures. Additionally, the subtype differences and heterogeneity inherent in the $\mathrm{CHI}$ population may only be identified on such measures (Sarno, 1980). The heterogeneity of these CHI subjects is increasingly well recognised and Sarno's $(1980 ; 1984)$ classification provides further evidence for the fact that there is no one type of language disturbance resulting from closed-head injury.

Hagen (1984) has viewed the language problems of the closed- head injured from a very different perspective to that of Sarno $(1980 ; 1984)$. He has argued that $\mathrm{CHI}$ is characterised by 'confused' language or "a receptive/expressive language that may be intact phonologically, semantically and syntactically yet is lacking in meaning because the behavioural responses are irrelevant, confabulatory, circumventory and tangential" (Hagen, 1984: 246). It appears from this definition that the language disorder extends beyond a problem of language form or content, and that the disturbance may be reflected in another area such as that of language function or use. Milton, Prutting and Binder (1984) have supported this view and have stated that the CHI subject is communicatively incompetent since language function is typically impaired in this population. They have adopted the premise that language may be divided into the components of form or structure, content and usage. Through adopting a more holistic view of language as a component of communication, they have identified the use of language in social context as the major area of deficit in subjects with closed-head injury.

This broader communication problem of the $\mathrm{CHI}$ population has been attributed to one or more of the following factors psychiatric disturbances, memory problems or a pervasive cognitive deficiency (Russell, 1971; Holland, 1982). Ylvisaker and Holland (1985) have recently suggested that the language disruption is secondary to a deficit in conceptual or cognitive processing. While previous research has recognised the existence of cognitive problems such as poor abstract thought and slow speed of processing in CHI subjects (Hagen, 1984), the contention of a causal relationship is novel. The nature of the relationship between language disturbance and the cognitive deficit remains unresolved. It is, however, a critical issue in terms of rehabilitation of these subjects.

The purpose of this study therefore is to examine the language disorder resulting from closed head-injury in relation to the holistic concept of communicative competence as well as in relation to cognitive functioning. It is submitted that a description of the language disturbance from a broader perspective is valuable from a theoretical perspective. Furthermore, the clearer definition of the nature of the disturbance should be of assistance in the future management of the $\mathrm{CHI}$ individual. 


\section{METHOD}

SUBJECTS

Three English-speaking adult males who had sustained closedhead injuries as a result of motor vehicle accidents were selected as subjects for this study. The ages of the subjects ranged between 24 to 27,4 years (mean 25,2 years). Mean coma duration of the subjects was 11 weeks (range $3-21$ weeks), thus indicating a severe head injury according to the criteria prescribed by Russell (1971). All subjects were neurologically stable at the time of testing with a mean post-injury time of 39 months (range 15-52 months). Subjects were all pretraumatically right handed and had completed at least eleven years of schooling. Family reports indicated that subjects were of average intellectual capacity prior to the accident. No previous history of sensory or motor deficit was reported nor was any history of drug or alcohol abuse noted. Hearing was within normal limits for all three subjects at the time of testing. Further relevant clinical and biographical details are included in Table 1 below.

Table 1: Relevant clinical and biographical details for all subjects

\begin{tabular}{|c|c|c|c|}
\hline Age & $\begin{array}{c}\text { Subject } 1 \\
24 \\
\end{array}$ & $\begin{array}{c}\text { Subject } 2 \\
24.1 \\
\end{array}$ & $\begin{array}{c}\text { Subject } 3 \\
27.4\end{array}$ \\
\hline Sex & Male & Male & Male \\
\hline Premorbid laterality & Right & Right & Right \\
\hline Educational level & Standard 9 Apprentice mechanic & Matric & Diploma in electronics \\
\hline $\begin{array}{l}\text { Time since injury to } \\
\text { testing (months) }\end{array}$ & 15 & 52 & 50 \\
\hline Coma length (weeks) & 3 & 10 & 21 \\
\hline Present motor problems & $\mathrm{L}$ arm hemiplegia & $\begin{array}{c}\text { Bilateral paresis of } \\
\text { both arms }\end{array}$ & $\begin{array}{c}\text { Bilateral extreme } \\
\text { spasticity }\end{array}$ \\
\hline Occupation & Unemployed & Unemployed & Unemployed \\
\hline $\begin{array}{l}\text { Receiving speech } \\
\text { therapy }\end{array}$ & Yes, since May 1983 & No therapy presently & Yes, since November 1980 \\
\hline $\begin{array}{l}\text { Immediate post-trauma } \\
\text { CAT scan results }\end{array}$ & $\begin{array}{l}\text { Diffuse cerebral oedema } \\
\text { with small parieto- } \\
\text { temporal bleed on left. }\end{array}$ & $\begin{array}{c}\text { Diffuse cerebral oedema } \\
\text { and high intracranial } \\
\text { pressure. }\end{array}$ & $\begin{array}{c}\text { Extensive cerebral } \\
\text { involvement including } \\
\text { brain stem and right } \\
\text { cortical areas. }\end{array}$ \\
\hline
\end{tabular}

\section{TESTING}

As there are no language tests currently available for the specific assessment of $\mathrm{CHI}$, it was necessary to utilise and modify tests designed for other disorders such as aphasia. The following tests were administered in order to evaluate the communicative and cognitive functioning of the subjects:

a. Language form testing - this involved the administration of the Boston Diagnostic Aphasia Examination (Goodglass and Kaplan, 1972) which was utilised to provide an overall account of the language pattern of the subjects. More specific receptive language testing comprised the administration of the Revised Token Test (McNeill and Prescott, 1978) and a linguistic test designed to measure performance on complex sentences (Penn, 1972). This latter test is designed to assess competence with respect to complex sentences such as relative and complement constructions. The subject was required to answer questions about each of the twenty seven sentences presented to him. Sentences were analysed by drawing the deep syntactic structure of the sentence and by observing at what point the subject failed.

Expressive language testing involved the syntactic analysis of the subjects' output using the Language Assessment Remediation Screening Procedure (LARSP) (Crystal, 1982). The data for the analysis consisted of a spontaneous interactive language sample which was elicited by one of the authors and simultaneously videotaped and audiotaped through a one-way mirror set-up. Topics such as the subject's accident, his family structure, and his hobbies and interests were discussed during this conversational interchange. The sample was then transcribed according to the suggestions of Crystal, Fletcher and Garman (1976) and profiles were completed for each subject. Further expressive language testing involved the administration of the expressive component of the linguistic test designed to assess the subject's performance on complex sentences (Penn, 1972). The subject was required to repeat twenty five complex sentences and responses were analysed both qualitatively and quantitatively.

b. Language use testing consisted of the administration of the Communicative Abilities of Daily Living (CADL) (Holland, 1980). In addition, the interactive sample was analysed on a protocol of communicative skills, the Profile of Communicative Appropriateness (Penn, 1983). This profile rates the subject's responses to the interlocutor, control of semantic content, cohesion, fluency, sociolinguistic sensitivity and non-verbal communication. (See Table 2 for example of this profile.) 
Table 2: Profile of Communicative Appropriateness (Penn, 1983)

Name

Date

Person eliciting sample
Features of sampling

Unit of analysis

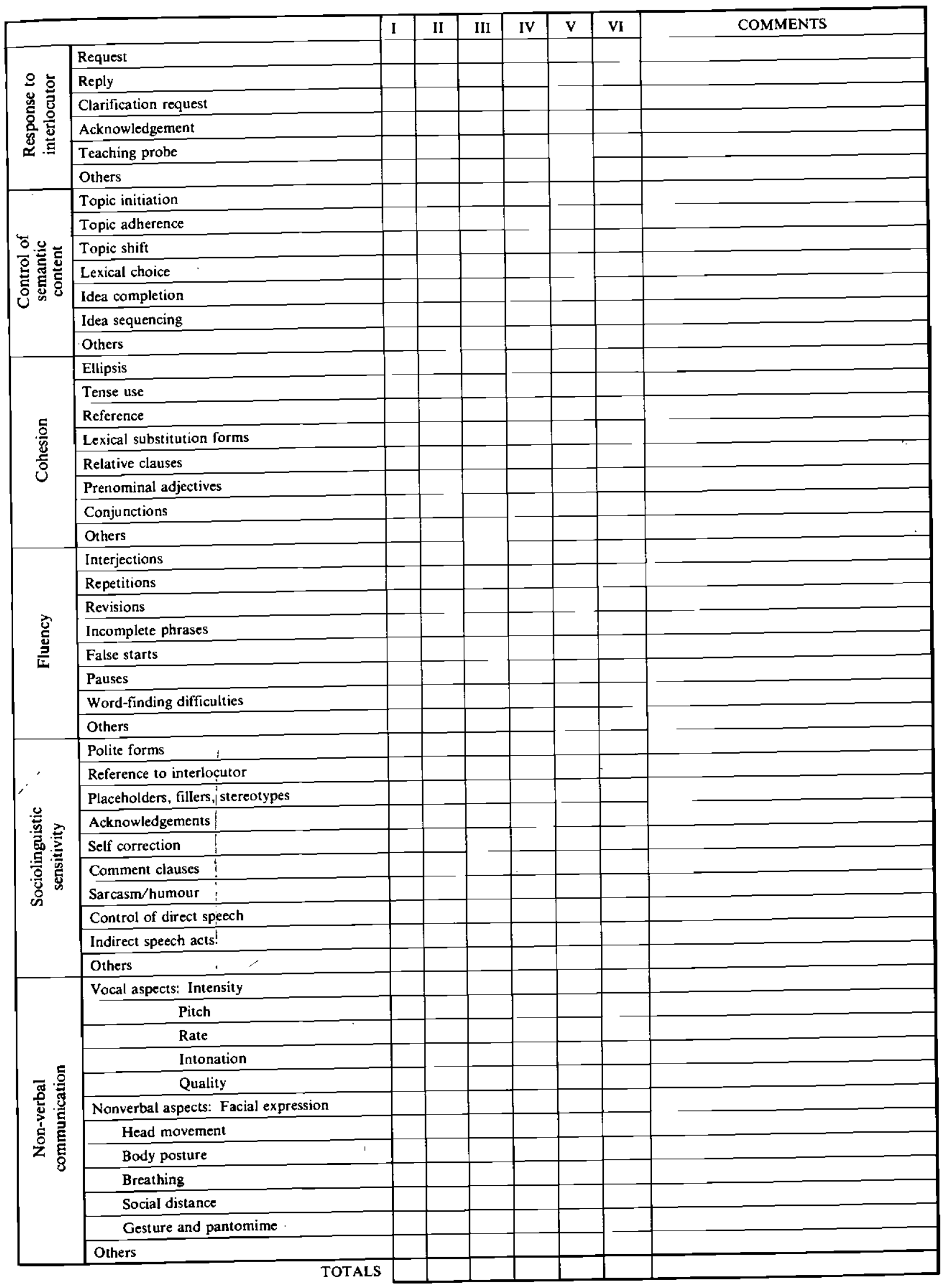

Key:
I = Inappropriate; II = Mostly appropriate; $\mathrm{III}=$ Some appropriate; $\mathbf{I V}=$ Mostly appropriate; V = Appropriate; $\mathrm{VI}=$ One. 
The ratings on this profile were completed by two trained speech and language pathologists who observed the videotapes independently and then completed the score sheet according to their observation of the relevant dimensions. Both raters had been trained in the use of the profile with the inter-rater reliability being calculated at 0.92 (using the Pearson Product Moment Correlation) and hence significant beyond the 0.05 level of significance. Communicative competence was analysed quantitatively by computing the overall ratings of appropriate and inappropriate behaviours.

c. Cognitive testing consisted of the administration of the South African Wechsler Adult Intelligence Scale - S.A. WAIS (National Institute of Personnel Research 1969). Scoring was completed according to the prescribed procedure.

Testing was carried out individually and extended over a number of morning sessions in an attempt to eliminate fatigue as a confounding variable. In order to reduce anxiety, rapport was established with each subject prior to his being tested.

\section{RESULTS}

The overall results across the language tests are presented in Table 3. In order to allow for comparisons between very different tests and to obtain an overall view of the subjects' performance, the results are presented qualitatively. Thus, performance is classified as being either good, mediocre or poor.

Table 3: Results of subjects' performance on receptive and expressive language testing

\begin{tabular}{|l|c|c|c|}
\hline \multirow{2}{*}{ TEST } & \multicolumn{3}{|c|}{ RESULTS } \\
\hline & Subject 1 & Subject 2 & Subject 3 \\
\cline { 2 - 4 } & - & + & + \\
\hline Revised Token Test & - & + & +- \\
\hline $\begin{array}{l}\text { Complex sentences - } \\
\text { Comprehension }\end{array}$ & - & + & +- \\
\hline $\begin{array}{l}\text { Spontaneous speech - } \\
\text { LARSP profile }\end{array}$ & - & + & + \\
\hline $\begin{array}{l}\text { Complex sentences - } \\
\text { Expression }\end{array}$ & - & + & + \\
\hline
\end{tabular}

\begin{tabular}{|c|}
\hline Key: \\
$+=$ Good performance \\
$\pm=$ Mediocre performance \\
$-=$ Poor performance
\end{tabular}

\section{a. Language form testing}

The profiles obtained for the subjects on the BDAE were atypical of the aphasic syndrome profiles described by Goodglass and Kaplan (1972). Subjects 2 and 3 (Ss2 and 3) were credited with a severity rating of 4 indicating some loss of facility in speech and comprehension. S2 and S3 performed similarly on the various subtests. They showed above mean performance on all subtests with the exception of the verbal agility, animal naming and writing mechanics sections. It is possible that the poor verbal agility score is attributable to the dysarthria which both subjects demonstrated. Levin (1981) has observed that a dysarthria frequently accompanies language disturbance in the early stages of recovery post-CHI and may persist following language restoration.

Subject 1 was given a severity rating of 2 , suggesting that conversation about familiar subjects is possible although many exhibit a recognisable aphasic profile but problems in both comprehension and expression were observed, a common finding of CHI (Levin, 1981).

The results of the receptive language tests revealed a variation in performance across subjects but consistency across tests. On both the Token Test (McNeil and Prescott, 1978) and the receptive section of the linguistic test for complex sentences (Penn, 1972), a severe impairment was noted for SI (scores 8 and $45 \%$ on the two tests), a moderate receptive language deficit was recorded for $\mathrm{S} 3$ (scores 13 and $80,5 \%$ ) and almost intact language reception was noted for S2 (scores 15 and 96\%). Holland (1982) has stated that language comprehension problems may persist well into the recovery phase following $\mathrm{CHI}$ and that comprehension breaks down as the complexity of the material increases. A qualitative analysis of the results of the present study revealed that no one sentence type or grammatical construction presented more difficulty than any other, although increased sentence length was more problematic for all subjects. This may have resulted from short term memory problems, a recognised concomitant of $\mathrm{CHI}$ (Hagen, 1984). Table 4 below sets out the major results of the LARSP analyses (Crystal 1982) for all subjects.

Table 4: Results obtained by all subjected on the Revised LARSP profile (Crystal 1982).

\begin{tabular}{|c|c|c|c|}
\hline Total number sentences & $\begin{array}{c}\text { SI } \\
313\end{array}$ & $\begin{array}{l}\text { S2 } \\
142\end{array}$ & $\begin{array}{r}\text { S3 } \\
142\end{array}$ \\
\hline $\begin{array}{l}\text { Mean number sentences } \\
\text { per turn }\end{array}$ & 4,6 & 7,9 & 2,2 \\
\hline Mean sentence length & 4,17 & 10 & 7,4 \\
\hline Total spontaneous utterances & 174 & 125 & 80 \\
\hline Number of clauses & 198 & 212 & 152 \\
\hline Number of phrases & 551 & 698 & 465 \\
\hline Number of word endings & 263 & 276 & 205 \\
\hline
\end{tabular}

As is evident from this table, Ss 2 and 3 presented with well preserved expressive syntactic skills. They demonstrated retention of all constructions with equal balance between phrase, word and clause levels. Both these subjects exhibited a high frequency of Stage $V$ utterances as well as utterances at Stages VI and ViI. Few (-) features were marked and both demonstrated a high frequency of spontaneous utterances. Sections B and D of the profile revealed less interaction with the conversational partner for $\mathrm{S} 2$ than for $\mathrm{S} 3$.

SI presented with a definite expressive syntactic breakdown as evidenced by his LARSP sample. He exhibited a high percentage of problematic and unanalysed utterances, a shorter mean sentence length than the other subjects and a high proportion of utterances around Stage $\mathrm{V}$ with few utterances beyond this stage. Many ( - ) features were marked including omissions and concord errors.

The results of the expressive section of the linguistic test of complex sentences supported the above findings. Subjects 2 and 3 scoring $80 \%$ and $76 \%$ respectively, while S1 scored $0 \%$. SI was often unable to recall linguistic elements. In addition, he tended to produce the incorrect word order of the sentence. It is possible, however, that his poor performance resulted from his inability to cope with the memory demands of the task. Thus his langauge impairment may be secondary to cognitive disorganisation - an acknowledged pattern of breakdown (Hagen, 1984; Ylvisaker and Holland, 1985) 


\section{b. Language use testing}

The results of the CADL (Holland, 1980) revealed relatively well preserved functional skills for all three subjects. This finding was unexpected in view of the results of Milton et al. (1984) who proposed that $\mathrm{CHI}$ leads to an impairment in pragmatic skills. However, these writers used a societal rather than a clinical profile and this renders comparisons impossible.

Percentage values were computed from the raw scores of the
CADL SI scored $96 \%$ followed by S2 who scored $94 \%$ and finally, $\mathrm{S} 3$ who obtained $86 \%$. Depressed scores were noted on the divergences items as well as on the humour, metaphor and absurdity items. Holland (1982) has stated that these items rely on subtle reception of language. The inability to comprehend such items was noted in all three subjects.

The results of the Profile of Communicative Appropriateness (PCA) (Penn, 1983) supported the findings of the CADL (see Figure 1 below).

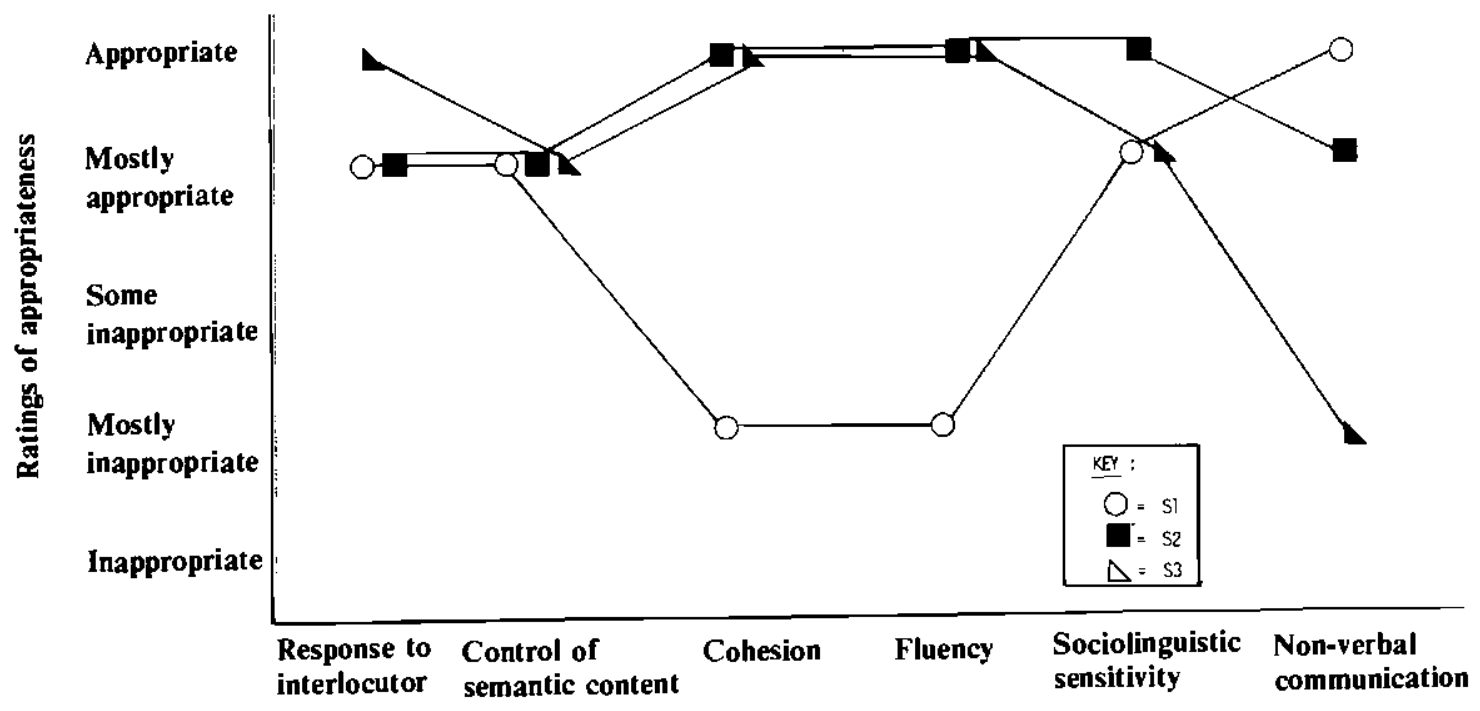

Dimensions of PCA

Figure 1: Performance of all three subjects on the Profile of Communicative Appropriateness

The ratings suggested that all three subjects exhibited relatively well preserved communicative abilities. Specific areas of breakdown were noted for all the subjects and although these deficits were not overriding, they were sufficient to penalise the subjects in a conversational context. SI was rated as mostly inappropriate on the Cohesion and Fluency scales, possibly as a result of his anomic and syntactic deficits. He was rated as appropriate on the Nonverbal Communication scale and mostly appropriate on the Response to interlocutor, Control of Semantic Content and Sociolinguistic Sensitivity scales. S2 demonstrated certain problems in interaction largely owing to dysarthria and apparent insensitivity to the interlocutor. Apart from poor non-verbal communication, $\mathrm{S} 3$ demonstrated well preserved pragmatic skills. Some difficulties were noted with suprasegmental features such as vocal intonation, quality and rate of output. Once again, this may be attributed to the presence of a dysarthric component in his speech pattern.

The differing patterns of performance and the relative preservation of the most pragmatic skills on the PCA is unexpected in view of the recognised broad nature of the language deficit of CHI. Pragmatic abilities are reportedly depressed in the CHI population (Holland, 1982) and often serve as the pivotal differential diagnostic feature between $\mathrm{CHI}$ and aphasia. The above findings indicate that pragmatic skills are not completely preserved in any one subject and that whilst an impairment exists, it is not as severe as has been documented in the literature (Holland, 1982; Milton et al., 1984). The difference between the results of the present study and previous research may be attributable to the fact that different studies utilise differing profiles for analysis and different contexts for data elicitation.

\section{c. Cognitive testing}

Results of the cognitive testing indicated that each subject had suffered a certain degree of intellectual impairment although the exact degree was subject-specific. S1 obtained a full scale IQ score of 75,5 whereas S2 scored 102,5 and S3 scored 82,5. Since all subjects had completed at least 11 years of schooling and their families reported no pretraumatic intellectual deficit, one may assume that the depressed cognitive results are associated with the head injury. These findings are supported by Hagen (1984) and by Levin. Benton and Grossman (1982) who stated that intellectual impairments are the major residual feature of $\mathrm{CHI}$.

Sl's functioning was borderline and a close correlation was noted between his verbal and performance scores. He performed poorly on those tests which required memory skills for example, the digit span and repetition tests. S2 performed at an average level and there was good agreement between his verbal and performance scores. As with S1, S3's functioning was borderline and while his verbal score was average, his performance score was much poorer. $\mathrm{He}$ demonstrated impaired functioning on all tasks involving spatial-synthetic and visual-constructive abilities. Although Ss 1 and 3 performed comparably on the cognitive testing, their language skills differed markedly. This suggests no direct relationship between language abilities and cognitive performances.

In sum, the results of the testing in all three areas revealed different patterns of performance for all three subjects. All subjects presented with a degree of language impairment in both form and use. The nature and degree of the impairments, and the balance between language structure and language use skills was subject-specific. These varying patterns lend support to the notion 
of heterogeneity within this population (Sarno, 1980: 1984). Cognitive impairments were noted in all subjects thus supporting the finding of Sarno (1980) that "while aphasia sometimes occurs in $\mathrm{CHI}$, the far more predominant language disturbances are those that result from the cognitive impairment itself."

\section{DISCUSSION}

SI performed poorly across all tasks with the exception of his score on the CADL (Holland 1980). His results parallel Levin et al.'s (1982) finding that patients with a generalised language impairment present with depressed functioning as noted on both the verbal and performance scores of the WAIS (NIPR 1969). S2 performed well in all the areas tested with the exception of specific problems in interaction such as insensitivity to the interlocutor. These results suggest relatively good preservation of language form, use and cognitive skills. It is hypothesised, however, that the few areas of deficit noted on the language use tasks are sufficient to reduce communicative competence and to impede the free flow of conversation. S3 presented with an inconsistent pattern in that he performed relatively well in the areas of language expression and pragmatic skills but exhibited some problems in subtle reception and in cognitive processing.

There are several possible explanations for this variation in performance. Coma duration and neurological dynamics could possibly account for the differences, as each subject presented different types of brain damage. Other variables which may play a significant role in the explanation are non-medical variables such as motivation and personality functioning since affective disorders are a well recognised by-product of CHI (Hagen, 1984; Sarno and Levin, 1985). A crucial feature which appears to be operating, however, is the degree of cognitive impairment. This seems to be the main indicator of retention of language skills. It seems from the results that there is a close relationship between the degree of cognitive deficit and the retention of language skills.

The variablity of the findings may also be attributed to the fact that the closed-head injured group are a heterogenous group and that individual patterns rather than a single group pattern characterizes this population. This notion is considered in the CHI literature (Sarno, 1980; Sarno and Levin, 1985) and is becoming increasingly well accepted.

A further issue which must be addressed is that of the crucial relationship between language use and language form skills. There does not appear to be a clear dissociation between these as has been suggested in previous studies (Milton et al., 1984). This discrepancy gives rise to further debate concerning the applicability of pragmatic competence as a differential diagnostic feature between aphasia and closed-head injury.

\section{CONCLUSION}

The finding that cognitive deficits are a predominant sequela of the closed-head injured population is consistent with the literature (Ylvisaker and Holland, 1985). The results of this study suggest that there is no one type of language disorder associated with CHI but that the interaction between language use and language form skills are subject-specific and may be attributed to other factors such as cognitive impairment. The implications of this finding for remediation are many. In view of the heterogeneity, it is essential that the clinician assesses each closed-head injured subject individually without relying on the predicted findings from the literature. Furthermore, it is essential to decide whether the cognitive dysfunction should be remediated if it underlies the language disturbance or whether the surface language symptoms should be treated.

There are many questions and too few answers at this stage. There is little doubt, however, that CHI presents the speech-language pathologist with a "unique and complex diagnostic, prognostic and treatment challenge." (Hagen $1984: 245$ ).

\section{REFERENCES}

Annegers, J.F., Grabow, J.D., Kurland, L.T. and Laws, E.R. The incidence, causes and secural trends of head trauma in Olmsted County, Minnesota. Neurology, 30, 912-919, 1980.

Crystal, D., Fletcher, P. and Garman, M. The Grammatical Analysis of Language Disability: A procedure for Assessment and Remediation. London: Edward Arnold, 1976.

Crystal D. Profiling Linguistic Disability. London: Edward Arnold, 1982.

Goodglass, H. and Kaplan, E. Boston Diagnostic Aphasia Examination. USA: Lea and Febiger, 1972.

Hagen, C. Language Disorders in Head Trauma. In A. Holland (Ed.) Language Disorders in Adults. Houston: College Hill Press, 1984.

Holland, A. Communicative Abilities of Daily Living - A Test of Functional Communication for Aphasic Adults. Baltimore: University Park Press, 1980

Holland, A. When is Aphasia Aphasia? The Problem of Closed Head Injury. Paper presented at the Conference of Clinical Aphasiology, Oshkosh, Wisconsin, 1982.

Levin, H.S. A phasia in Closed Head Injury. In M.T. Sarno (Ed.) Acquired Aphasia. New York: Academic Press Inc., 1981.

Levin, H.S., Benton, A.L. and Grossman, R.G. Neurobehavioural Consequences of Closed Head Injury. Oxford: Oxford University Press.

Luria, A.L. Traumatic Aphasia: Its Syndromes, Psychology and Treatment. The Hague: Mouton, 1970.

McNeil, M.R. and Prescott, T.E. Revised Token Test. University Park Press, Baltimore, 1978.

Milton, S.B., Prutting, C.A. and Binder, G.M. Appraisal of Communicative Competence in Head Injured Adults. Paper presented at the Clinical A phasiology Conference, Seabrook Island, California, 1984.

National Institute for Personnel Research South African Wechsler Adult Intelligence Scale. Translated and adapted with permission, 1969.

Penn, C. A linguistic approach to the detection of minimal language dysfunction in aphasia. Unpublished Undergraduate Research Report, Department of Speech Pathology and Audiology, University of the Witwatersrand, 1972.

Penn, C. Syntactic and Pragmatic Aspects of Aphasic Language. Doctoral thesis, Department of Speech Pathology and Audiology, University of the Witwatersrand, 1983.

Russell, W.R. The Traumatic Amnesias. London: Oxford University Press, 1971.

Sarno, M.T. The Nature of Verbal Impairment after Closed Head Injury. Journal of Nervous Mental Disorders, 168, 685$692,1980$.

Sarno, M.T. Verbal improvement after CHI: report of a replication study. Journal of Nervous Mental Disorders, 172, 475$479,1984$.

Sarno, M.T. and Levin, H.S. Speech and Language Disorders after CHI. In J.K. Darby (Ed.) Speech and Language Evaluation in Neurology: Adult Disorders. New York: Grune and Stratton, 1985.

Ylvisaker, M. and Holland, A.L. in D.F. Johns (Ed.) Clinical Management of Neurogenic Communicative Disorders. Boston: Little Brown and Co., 1985. 


\section{NEW from AMTRONIX -}

\section{Computerized Impedance System}

\section{Features}

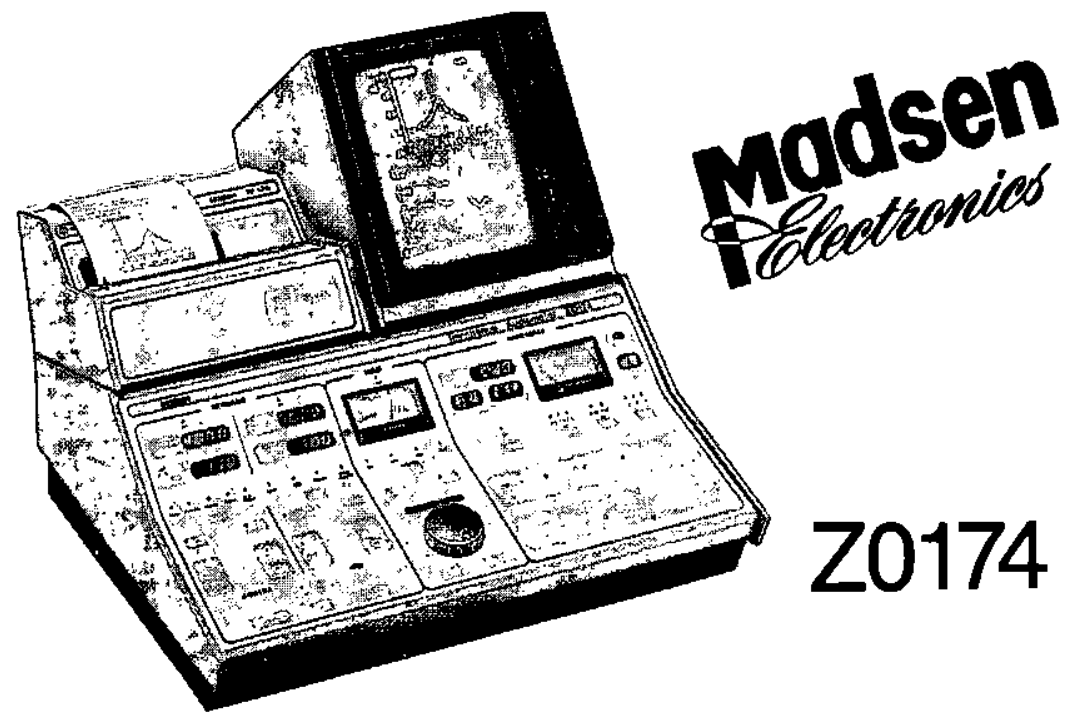

Analog meters for compliance and pressure permit easy visualising of test.

- Digital displays for ear canal volume and static compliance.

- Tympanometric pressure may be read digitally.

- Tympanometric gradient is calculated and digitally displayed.

- Digital displays for frequency and intensity for stimuli.

- Expanded reflex mode reveals latency, amplitude, growth and morphology.

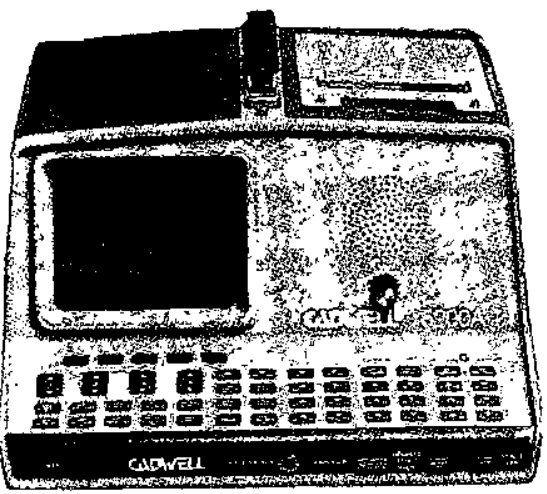

Auditory Evoked Response - to evaluate middle- and late-latency responses from the higher centers of the cortex

\section{Evoked Potential Testing with Cadwell Instrumentation}

\section{Objective Detection of Audiologic and Vestibular Dysfunction}

\section{The Simple Solution for Complex Audiologic Cases}

ENG - to evaluate central and peripheral vestibular dysfunction

BSEP - to objectively

localize deficits to the cochlea, the auditory nerve, or the brainstem auditory pathways

40-Hertz Evoked Response Audiometry - to objectively measure hearing thresholds
Electroneurography - to obtain objective measurements of facial nerve function

\section{Pac AUDIOMETRIC ROOMS}

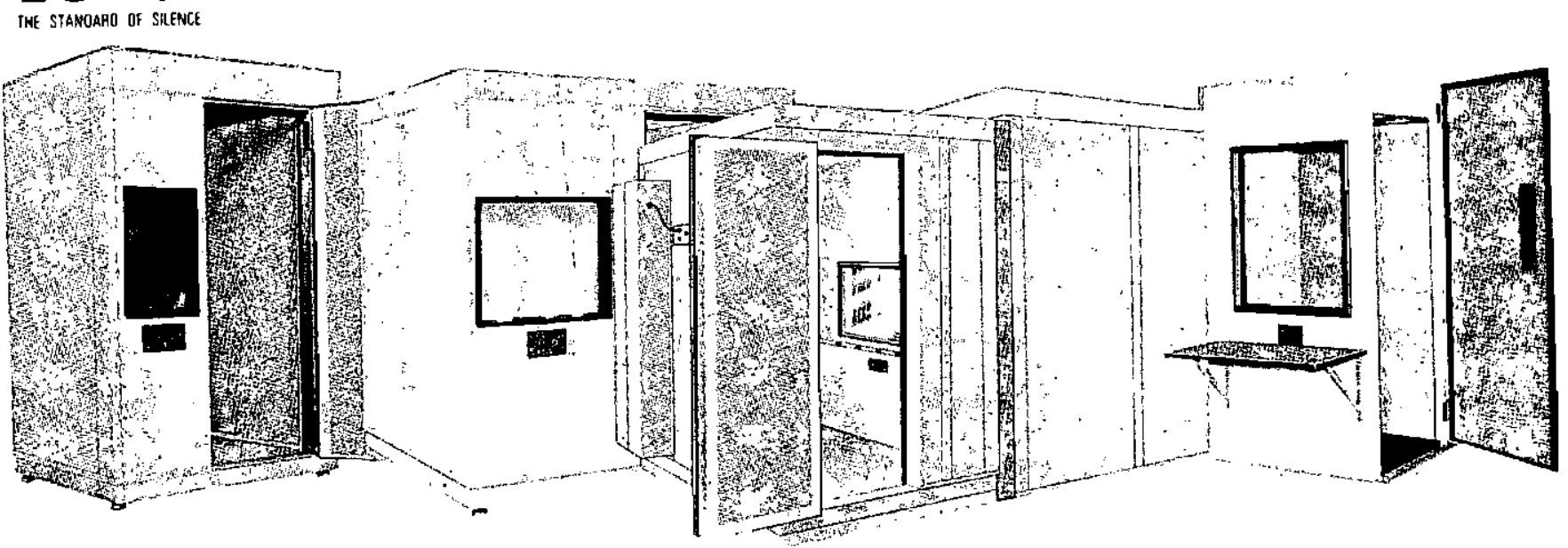

